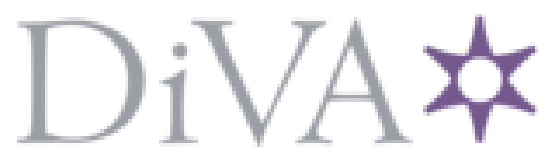

http://www.diva-portal.org

\title{
Postprint
}

This is the accepted version of a paper published in Epoché: A Journal For the History of Philosophy. This paper has been peer-reviewed but does not include the final publisher proof-corrections or journal pagination.

Citation for the original published paper (version of record):

Weigelt, C. (2013)

The Hermeneutic Significance of Aristotle's Concept of Chance.

Epoché: A Journal For the History of Philosophy, 18(1): 29-48

http://dx.doi.org/10.5840/epoche201318116

Access to the published version may require subscription.

N.B. When citing this work, cite the original published paper.

Permanent link to this version:

http://urn.kb.se/resolve?urn=urn:nbn:se:sh:diva-20125 
Charlotta Weigelt

Stockholm University

\section{The hermeneutic significance of Aristotle's concept of chance}

I

Aristotle's views on chance (tuchê), elaborated most notably in the second book of the Physics, present his readers with several difficulties. As the extant literature on this subject clearly shows, it is far from obvious what kind of causality is involved in chance events, and it has proved to be no small task even to decide whether or not Aristotle is at all prepared to acknowledge the existence of such things as chance and spontaneous generation, since that seems to go against his own theory of causation. ${ }^{1}$ Another peculiarity, which in my view has so far not been given the attention it deserves, is that Aristotle in the Physics introduces his discussion of chance and spontaneity by raising the question whether or not these phenomena are to be counted as genuine natural causes, that is, on the same level as the formal, the material, the efficient and the final cause respectively, but then locates chance entirely within the realm of human praxis, making it into a sub-species of spontaneity (automaton), that which happens of itself. For granted that spontaneous events in general belong to that which happens for the sake of something, chance may be defined, Aristotle claims, as that which makes its appearance in cases "when something that can be an object of decision happens of itself to creatures endowed with the capacity of making decisions."

At the same time, however, the account of chance that Aristotle offers us in the Physics involves a perspective on human agency which does not immediately fit into his teleological model of action, and which might therefore seem to complicate or even to challenge it. For on that model, action essentially consists in the realization of a given end, which is anticipated in advance and then led back to the agent as to the ground or origin (archê) of action as a goaldirected activity. But chance, being unexpected and unpredictable, constitutes an external factor beyond the agent's control, thus cannot be traced back to the agent as to its ground, and it also forces us to reevaluate any given action with respect to both its cause and its result, in that it in retrospect, so to speak, replaces the originally intended end with another, incidental end, which was actually not intended by anyone but just happened to be realized. In this way, the phenomenon of chance seems to contradict the very notion of finality commonly associated with Aristotle's theory of action. More than one commentator has therefore concluded that chance precisely entails the absence of ends serving as final causes. ${ }^{3}$

Aristotle himself undoubtedly considers chance events to be rare: they do not belong among the things that "happen always or for the most part in the same way." Nevertheless, I want to suggest that chance, at least as characterized in the Physics, is not some marginal or mystical phenomenon, but actually a very common sort of thing. For this reason, it has to be taken seriously if one wants to properly understand Aristotle's conception of action as a whole, and in particular his notion that the agent himself is the ground of his actions. 
In this article, I want to call attention to what I consider the "hermeneutic significance" of Aristotle's concept of chance. With this expression, I mean to indicate that Aristotle's discussion of chance will here be taken as an incentive to raise anew the question concerning the proper method or perspective for a theory of action. More specifically, my aim is to show how the phenomenon of chance, such as it is described in the Physics, calls into question the possibility of explaining action and its teleological structure from a third-person point of view. Beginning with what might seem to suggest that precisely such an approach is actually central to Aristotle's theory of action as developed in the Nicomachean Ethics, I then try to show how this approach is challenged by the analysis of chance action in the Physics. What emerges from this analysis is not merely a picture of human finitude, in the sense that the realm of human agency is found to be governed by external and unpredictable factors against which man is powerless, but even what seems to be a demonstration to the effect that chance actions do not qualify as actions at all, since they apparently lack the structure of rational deliberation and intentionality that, to judge from the Nicomachean Ethics at least, constitutes prâxis in the proper sense.

In the face of this predicament, I argue that rather than concluding, as is sometimes done, that chance presents us with an irresolvable aporia or perhaps a peculiar subset of human action, we should take it as an invitation to reconsider the meaning of ground or archê in connection with human agency. To make the case of chance consistent with Aristotle's theory of action as a whole, we have to reinterpret the latter in such a way that the agent's role as the archê of his or her actions is understood along the lines of rational and moral responsibility, rather than in objective and metaphysical terms. To act then means to respond to the external circumstances of action, as for example the appearance of chance or unforeseen ends: to make them one's own by assuming responsibility for them, even though one is not their origin in ontological respect. But this means that chance itself must be conceived of as a subjective phenomenon, as something that may appear in relation to an agent's anticipation of a specific course of action. If this is indeed the perspective taken on human praxis by Aristotle in the Physics, then this work in fact holds the key to the theory of action elaborated in the Nicomachean Ethics, namely, as it shows that this theory only makes sense when regarded as an attempt to explore the realm of human praxis from within the agent's own point of view. ${ }^{5}$

II

In the Nicomachean Ethics, Aristotle claims that "man is the origin of his actions" and that "we are the masters of our actions from the beginning right to the end." On closer scrutiny, however, this proves to be true of voluntary actions alone, for Aristotle also recognizes the possibility of involuntary action, whose defining mark is that it has an external origin or ground (archê exôthen, E.N. 1110a1). But in a work on ethics, it is natural to focus on the class of voluntary action, for this is where we find the actions that can be subject to praise and blame (E.N. 1109b31). And the demarcation of voluntary action paves the way for that conception of action which has become the hallmark of Aristotelian virtue ethics: action based on reasoned, deliberate decision, which is a sub-species of the voluntary (E.N. 1111b6- 
8). It is because action is the realm of freedom that there is need for deliberation in the first place: there is no point in deliberating on things that are of necessity or happen by chance (E.N. 1112a27), but "we deliberate on what depends on us, that is, what we can do." which depends on us or is within our power to bring about is that which admits of different alternatives, and such things have their source and ground, their archê, in us. In the Eudemian Ethics, this is explained in the following way:

\begin{abstract}
Hence if in fact there are some things that admit of the opposite state, their origins [archai] must necessarily be of the same kind. ... And among the things that depend on men themselves, many are of this sort, and men are themselves the origins of such things. Hence it is clear that all the actions of which man is the ground [archê] and master may either happen or not happen, and that their happening or not happening depends on him, that is, those at least of whose existence or non-existence he is the master. But of what depends on him to do or not to do, he is himself the cause; and that of which he is the cause depends on him. ${ }^{9}$
\end{abstract}

It is because the agent himself is the source and ground of his actions that deliberation begins and ends with the agent. More precisely, the origin of an action is the agent's desire and conception $(\log o s)$ of an end, that for the sake of which the action will be performed, for it provides the agent with a reason for deciding in favor of a specific course of action. ${ }^{10}$ And when faced with a desirable end, he deliberates on how to achieve it, until he has led the origin or starting-point of the action back to himself, so as to make sure that the action constitutes a genuine possibility under the circumstances. At that point, the deliberation terminates in a conclusion, which has the form of a decision concerning how the action should be performed. The decision is, in short, the outcome of the deliberating process from unfounded to founded desire, and Aristotle therefore defines it as "deliberate desire" (bouletikê orexis, E.N. 1113a10-11).

Deliberation is essentially a search for means that will allow us to realize a given end, but the ends themselves are not up for deliberation: they present themselves to us as either desirable or unpleasant depending upon our character (E.N. 111211-12ff). Still, this does not make us victims of our desires, or in general of our character, for as agents we are able to give a rational and critical response to them. ${ }^{11}$ That is to say, our desires cannot merely be thought of as the efficient causes of our actions, thus as operating behind our back, as it were, but when entering the realm of intentional agency, they become "deliberate desires" or reasons for action. That is why we can be held responsible for them (E.N. 1114b30-a3).

That action, prâxis, in the proper sense is what lies within the agent's power also means that action is a unified phenomenon in a way that production, poiesis, is not. Just like the objects of nature have within themselves the ground (archê) of their own motion (Phys. 192b13-14), the basic trait of action is that its governing principle is located in the agent and in this way is internal to the activity itself. By contrast, production is governed by external causes: "its origin [archê] is in the producer and not in the product." 12 A process like that of making a statue is accomplished by a sculptor who is not in his turn affected by the production (the sculptor is not creating himself!), and the end of the process, the sculpture, is achieved only as the production process is finished. But an action is carried out for the sake of 
itself and not in order to produce anything beyond the action itself. As Aristotle also puts it: the end of action is simply eupraxia, successful action (E.N. 1139b3-4). In this way, the end or telos of an action is nothing different from the very action itself.

The unified, "finished" structure of prâxis indicates that human agency as opposed to production must be judged as well as explained solely on the basis of itself, so that every explanation of an action, every statement of what makes an action the kind of action it is, points back to the agent. Drawing upon Aristotle's theory of causation, we could say that the agent is where we should look not just for the source or efficient cause of a given action, but also for its end as well as its form or specific content. ${ }^{13}$

However, the idea that action does not point beyond itself in the same way as production and generation is apparently part and parcel of Aristotle's claim that action, properly speaking, is a self-sufficient or autonomous (autarkes) activity, which is indicated already in the first book of the Nicomachean Ethics. There Aristotle argues that the final good in life, eudaimonia, human flourishing or happiness, must be something that is desirable in itself and not merely as a means to something else. ${ }^{14}$ Besides, the achievement of happiness must be up to us, says Aristotle: it must be something we can attain by means of our actions, and therefore it cannot be identified with being granted a blissful destiny (tuchê). ${ }^{15}$

Insofar as action as such is self-sufficient in the sense of constituting a unified and complete activity, every virtuous action makes a contribution to the good life. Nevertheless, it seems that precisely the ideal of autarkia is what eventually makes Aristotle declare that the life devoted to contemplation, the bios theôrêtikos, is the supreme form of life, because contemplation is the most perfect and self-sufficient of all human activities:

The so-called self-sufficiency must first of all apply to the activity of contemplation. The wise man must certainly have the necessities of life, just like the just man and everybody else, ... but the just man needs people towards and with whom he may act justly, and the same goes for the sensible man, the brave man, and so on, whereas the wise man is capable of contemplation even when by himself, and the wiser he is the better he can do it. Probably he can do this better if he has fellow-workers, but nonetheless he is the most self-sufficient of all men. ${ }^{16}$

If Aristotle's theory of action is governed by an ideal of self-sufficiency and independence, it is not immediately clear how his theory should respond to what seems to be an obvious fact, namely, that our actions are at least in part conditioned by external circumstances, which Aristotle naturally would not dream of denying. But if he nonetheless tends to conceive of the distinction between action and production in terms of a difference between internal and external causation, it seems that he cannot acknowledge the presence of the latter within the realm of praxis without simultaneously exposing himself to the risk of dissolving that very distinction between action and production which he is so anxious to defend. In that case, we would have to say that Aristotle's theory of action is in fact based upon a model of production and craft, rather than being centered on questions about reasons and rationality. ${ }^{17}$

To come to grips with this problem, we have to try to interpret Aristotle's concept of archê in such a way that not merely fully autonomous action qualifies as action in the proper sense of the term. In this pursuit, however, the directives are given by Aristotle himself, namely in 
virtue of his account of chance in the Physics, which reveals the difficulty to make sense of action on the basis of a causalist approach that takes the model of production or natural generation as its clue.

\section{III}

Aristotle introduces his concept of chance - together with that of spontaneity - in the second book of the Physics, after having elaborated his theory of the four causes. The reason why he feels obliged to discuss whether or not chance and spontaneity are to be regarded as genuine causes is partly the very fact that this is a debated question, and partly because he is convinced that these phenomena have so far not been accurately understood. There are indeed such things as chance and spontaneity, Aristotle claims, though not in the sense one usually has believed. ${ }^{18}$ As already stated, things that happen by chance are, in Aristotle's view, unusual events, to be distinguished from those that happen always of for the most part in the same way, and it is the apparent fact that, once in a while, the unusual and unexpected does happen that makes Aristotle conclude that chance and spontaneity are phenomena to be reckoned with. But whereas earlier thinkers like Empedocles and Democritus treated chance as a possible efficient cause in nature, Aristotle from the beginning locates chance among the things that are for the sake of something, thus being conducive to some end: it is just that it happens by accident or kata sumbebêkos, instead of being the outcome of thought or nature (Phys. 196b21-24). In the Nicomachean Ethics, Aristotle accordingly remarks that chance and art (technê) in a way concern the same thing, for one and the same thing, e.g. health, can be the outcome of chance as well as of the art of medicine. ${ }^{19}$ In contrast to his predecessors, Aristotle does thus not want to posit chance as an objective cause in nature, for "in an unqualified sense it is not the cause of anything" (Phys. 197a14), but relates it instead to an experiencing subject or agent. ${ }^{20}$ This has made some of Aristotle's readers to conclude that he regards chance more or less as a subjective illusion, something we refer to when ignorant of the proper causes behind an event. ${ }^{21}$ But the fact that chance is not, strictly speaking, the cause of anything does not entail that it is just nothing. Or, as Pascal Massie puts it, "it is a nothing that changes everything. $" 22 \mathrm{We}$ do occasionally act by chance, there is no doubt about that, at least not as Aristotle sees it, but the question is what kind of action this is.

It should be noted that tuche is not a wholly neutral term for chance, but clearly carries the meaning of "luck," which is also how it is often translated. This sense of tuchê apparently dates back to Homer, where the verb tugchanô often is used in the sense of "being successful" in hitting the enemy, for example with bow and arrows or with a spear. ${ }^{23}$ In Aristotle's concept of tuche, there is undoubtedly a stronger emphasis on the element of accident and coincidence, though also in his view, what happens apo tuchês must be something good, for it is by definition something that we could have chosen to do under different circumstances, and we do not, at least not if we are rational beings, deliberately try to achieve something that seems bad to us. 
In order to explain his notion of chance, Aristotle asks us to imagine a case of a man's going to a market-place, whereby he happens to meet a person whom he wanted but did not expect to meet:

For example, a man would have gone [to the market-place] in order to retrieve his money when his debtor was collecting contributions, if he had known this. As a matter of fact, however, he did not go for this purpose, but it just happened by accident that he went away, and did this for the sake of collecting the money. For neither did he for the most part use to run off to the place, nor did he do this by necessity. Here there is no doubt an end, namely the recovery, but this is not one of the causes that are present in him, since an end is an object of decision and an outcome of thought. And so in this case, the man's going there is said to be the outcome of chance, whilst if he had made a decision and then gone there for the sake of this, alternatively always or for the most part used to go there, if would not be called the outcome of chance. ${ }^{24}$

What does it mean to say that something is the outcome of chance, thus implying that chance can be as it were responsible for what happens to us? Does not this by itself suggest an objective perspective on chance, as if it were some kind of power of its own? Certainly, but precisely by expressing himself in this way is Aristotle able to relate his own analysis of chance to that of his predecessors, as well as to ordinary linguistic usage, even though his ultimate aim is to reconsider the implications of this mode of expression.

An action may be said to be the outcome of chance when a person does something for the sake of some end (for example goes to the market-place in order to see a spectacle), though eventually discovers that the action in question in fact generated a result (meeting one's debtor and so getting the opportunity to collect one's money), which was not the intended one. Instead, the actual result, which could have constituted the end of his action (had he known that the debtor also was going to the market-place), was a matter of coincidence: it came about as a result of two different actions (two people going to the market-place for different reasons). In the above passage, Aristotle says that "the man's going there is said to be the outcome of chance," but to be more precise, it is the man's going to the place where his debtor was that happened by chance. ${ }^{25}$ For whereas his going to the market-place is a deliberate action, his meeting with his debtor is not, but nevertheless the meeting is "for the sake of" something, namely, the opportunity to retrieve the money, which constitutes the truly "lucky" event, as well as the final end, in this case.

But if we say that the man went "by chance" to the place where his debtor was and, as a consequence, got an opportunity to retrieve his money, and then ask that man what reason he had for acting in this way, he cannot answer, because there was not any reason behind this action (the agent never had the intention of finding his debtor). So once we begin to describe the action as a chance action, and thus as being actually conducive to an end that was not the intended one but just happened to be realized, any causes we can find are incidental causes, that is, insofar as they are related to the actual outcome of the action. As Aristotle says, maybe the man went to the market-place because he wanted to see someone, or was trying to follow or escape someone, or maybe he wanted to see a spectacle. (Phys. 197a17-18). It does not matter what reason the agent had for going to the market-place, because it was only by 
accident, kata sumbebêkos, that a particular wish, such as seeing a spectacle, made him go to a place where his debtor was. Hence, there is no intrinsic relation between a chance event and its efficient cause, but the latter is an unfulfilled final cause (wanting to see a spectacle) and so not the cause of the chance event as such (meeting one's debtor, etc.). ${ }^{26}$

Chance may now be defined, first, as that which happens for the sake of something, though it comes about by accident (Phys. 196b21-24). To clarify what he means by this formulation, Aristotle reminds us (at Phys. 196b24-29) of the distinction between being something in itself (kath' hauto) and being something incidentally or by virtue of concurrence (kata sumbebêkos), which distinction also applies to causes: the cause of a house is in itself a craftsman, but accidentally an educated man (if the craftsman happens to be educated). When applied to our case, this means that the wish to see a spectacle happened to be the - efficient cause behind the man's encounter with his debtor, because the man who encountered his debtor happened to have the wish to see a spectacle, which is not as such (kath' hauto) the cause behind the man's opportunity to retrieve his money. For the proper cause would consist in the wish to retrieve one's money, but as Aristotle says in the passage from the Physics quoted above, "this is not one of the causes that are present in him." Differently put: it is not as someone who wishes to see a spectacle that the man can be the cause of his meeting his debtor, except by virtue of concurrence, but as someone who wishes to get his money back.

Further, chance is a form of spontaneity, that which happens of itself, which Aristotle tries to capture with the following, somewhat paradoxical formulation: "Evidently, then, among the things that without qualification come to be for the sake of something, when something comes to be but not for the sake of the actual outcome, in that it has an external cause, then we say that it happened of itself." 27 Insofar as that which is achieved by chance could have formed the end of an action, it is "among the things that come to be for the sake of something," but insofar as the outcome of chance was actually not present at the outset, that is, as an end to be realized, the chance event does not come to be "for the sake of the actual outcome." Accordingly, it seems that we should say that chance events are such as to have beneficial or "lucky" results, but that they do not come about for the sake of these results, and therefore do not have any final causes. ${ }^{28}$ In this way, we avoid attributing to Aristotle the idea that an action may in fact constitute the realization of an end that was not intended by anyone, which would apparently make him guilty of a kind of objective teleology even within the realm of human agency (and not merely, as is often believed, within the realm of nature) and, accordingly, committed to the view that ends exist independently of their connections to intentions. $^{29}$

Insofar as chance is related to agency, one might think that even an action out of chance would have discernible reasons. However, it is clearly impossible to deliberately do something for the sake of a chance end, because the chance end is by definition not present to our minds as we deliberate on how to achieve some other end. Therefore, we are encouraged to think about chance in terms of something that happens of itself, and that is to say, more or less as an event or process in nature, in which we have no saying but which may causally affect us in different ways. But as we have seen, something that happens by chance only has 
incidental causes, which moreover are potentially infinite, for there is no limit to the number of accidental causes you may find behind an event. Hence, when regarded as an objectively existing phenomenon, chance appears as something indeterminate (aoristos, Phys. 197a21). It is an accidental cause, and the realm of accidental being is precisely something indeterminate and subjective, and as such it does not qualify as an object of scientific inquiry but, on the contrary, is where the sophists dwell (cf. Met. VII.2, 4). However, in concluding that chance is not a reality susceptible to scientific explanation but rather a matter of subjective impression, we seems to be back where we started: chance as related to human agency.

\section{IV}

Even though "it is evident that chance exists in some sense," 30 chance "seems to be concealed to man." ${ }^{31}$ But this is, I suggest, because we tend to conceive of agency on the basis of a causal perspective, which tendency Aristotle too is guilty of when he describes action in terms of self-sufficiency and autonomy. From that point of view, chance will emerge as something that presents an obstacle to our autonomy, to our ability to constitute the source and ground of our actions, at the same time as chance also is considered to actually not be the proper cause of anything, which implies that, after all, it cannot in fact threaten our autonomy as agents. For the moment, I leave the latter complication aside, and focus instead on how Aristotle's account of chance may be said to point out the limits of the agent's ability to be the origin and ground of his own actions, not to say go against his own theory of action as such.

To describe something as a chance event, or even as an action out of chance, it might seem necessary to move beyond the agent's own perspective, at least beyond the confines of the agent's own horizon at the moment when he is choosing the actual course of action. For at that time, he makes his decision on the basis of a certain intention, for example to see a spectacle, but the final outcome of this decision is an opportunity to retrieve his money, which means that his intention never gets fulfilled. ${ }^{32}$ Thus regarded, the full situation of the chance action is not accessible to the agent, for our description of the event as a chance action (accidentally coming across one's debtor) can only be given after the event has taken place, and is consequently not available to agent from the outset. This is because, although it was within the agent's power to choose a particular course of action, it was not within his power to fulfill the action in such a way as to realize the originally intended end, for this turned out to be replaced by another, chance end. And since it was certainly not within the agent's power to realize this end, the agent cannot be said to be the archê of his action in the sense of its origin or its governing principle: he did not set the action in motion, except accidentally, nor was he in control of it in the sense of realizing its rational structure, that is, choosing the means that make possible the accomplishment of the desired end (provided that we can speak about a rational structure in connection with chance actions at all). When acting out of chance, we are thus hardly "the masters of our actions from the beginning right to the end."

More precisely, since this setting in motion of the action did not lead to a realization of the expected end, not only do the agent's powers appear to be decisively limited, but it does not really seem that we are talking about a - complete - action at all. Granted that actions as such 
are directed towards some definite end, and when described as chance actions they do not have any ends, at least not in the sense of final causes, they seem to lose precisely the defining mark of action. If the action performed by the agent turns out to be, not that of seeing a spectacle, but that of meeting one's debtor and collecting money from him, then the agent was not the archê of that action. But how can one perform an action of which one is not aware that one is performing, that is, provided that we conceive of action as an intentional and rational activity, as opposed to mere physical behavior or motion? ${ }^{33}$ Still, this seems to be an unavoidable result in the case of chance, since chance is something incalculable (paralogos), something that cannot be counted upon in advance but happens contrary to our expectations, which means that it cannot form the object of any deliberation, the mode of reasoning that was supposed to govern our actions. ${ }^{34}$ For it seems very odd to speak about deliberation making action possible in cases when the agent does not even know the reason why he performs his actions. Indeed, it even sounds a bit awkward to say that one acts out of chance, since that seems to imply that one intentionally brings about a chance end, which is impossible. It cannot be within our powers to make a chance event come about, since chance is understood as that which happens by accident or by coincidence of two different and mutually independent actions.

In view of this, one might prefer to speak about chance events instead of chance actions, but Aristotle himself does not hesitate to say that we act "out of chance," as in the above quotation from the Physics, where the man's going to the market-place is said to have been "the outcome of chance" (the Greek phrase is apo tuchês elthein, more properly rendered as "went by chance"). And later, he states that "Both chance and the outcome of chance pertain to those who are able to succeed and, generally speaking, to act." 35 For this reason, Aristotle continues, those who lack the ability to act cannot make anything out of chance, which leads to the conclusion that neither lifeless things, nor animals or children, ever make anything out of chance, "for they lack the capacity of making decisions." 36

One possibility is perhaps to condemn chance actions as failed or involuntary actions. They may seem to be failed since one achieves something different from the initially desired end, and considering that Aristotle primarily conceives of and conceptualizes action from the vantage point of completed, successful action, working himself back to its initial state, that view may seem sustained. ${ }^{37}$ But they are not failed in the sense that nothing is achieved: indeed something good is achieved, it is just that it was not intended. Should we rather say that they are involuntary or unintentional? They are not involuntary in the sense of forced, but they do have an external ground, just like involuntary actions, and they are, to some extent at least, actions performed in ignorance, which also is a mark of involuntary actions (E.N. $1110 \mathrm{~b} 15 \mathrm{ff})$. Further, an involuntary action may receive the mark of ignorance in retrospect, namely if one regrets a previous action, just like a chance action is only eventually discovered to have occurred, as one relates the chance end to one's original intention (E.N. 1110b22-23).

But to think of chance actions as involuntary actions is not entirely satisfactory, considering that chance, as Aristotle describes it, actually seems to be a common phenomenon that has bearings upon the conditions of human agency as a whole, namely insofar as it is part 
of the human predicament constantly to be subjected to circumstances which we have not brought about ourselves, but to which we as agents nonetheless have to respond. If this is true, then Aristotle has to make room for chance within his account of action and, more precisely, show how he can still maintain that the agent is in some sense the ground of his actions: otherwise his theory of action is deprived of one of its most central tenets. Such a task no doubt requires that one is able to affirm the essential finitude of human agency and freedom. However, I believe that a more important implication of Aristotle's discussion of chance concerns our very conception of agency as a teleologically structured activity, namely, that it should not be elaborated on the basis of an objective perspective at all.

\section{$\mathrm{V}$}

In order to make sense of Aristotle's claim that it is possible to act out of chance, and in general to assess the implications of his account of chance for our conception of human agency, we must abandon the perspective on chance initially developed in the Physics, since when regarded as a possible efficient cause in nature, chance appears to be nothing real at all. ${ }^{38}$ More precisely, from an objective standpoint, one has to say that chance actions lack ends and, moreover, only have incidental efficient causes. But this is clearly intolerable on the teleological model of action, since it makes human agency seem like a completely indeterminate phenomenon. In view of this predicament, Pascal Massie has concluded that chance "occurs as a parody of teleology" and that chance events "mark the limit of a discourse on causality and teleology." 39 I agree with the latter statement, provided that the point of it is to say that chance marks the limits to our objective interpretation of teleology, but not of teleology as such. ${ }^{40}$

When Aristotle says that chance can only happen to creatures endowed with the capacity of making decisions, this means, I take it, that chance only makes sense to agents. Even though it is not possible to establish the occurrence of chance until the chance action has been completed, since the originally intended end was never achieved but got "replaced" by another, unforeseen end, this in fact does not mean that the happening of chance is inaccessible to the agent. On the contrary, the change of ends just mentioned is only possible to experience from within the situation of action itself, that is, from a first-person point of view. Objectively speaking, what we have here are two events (two men going to the marketplace for different reasons), and the intersection of these events constitutes a chance event only in the eyes of the agent who is out to realize a certain end and is able to experience how his action turned out to be for the sake of something which he never had in mind. So even though I as an agent am not the archê of that which happens to me by chance in the sense of being its cause, I am its arche insofar as I am the one who is able to understand the event precisely as a chance event, which is to say that I am the one who makes sense of chance as such.

When acting out of chance, we are subjected to the force of external circumstances of which we have no control, which shows that we are finite beings, so that we are not always, and perhaps never, completely the masters of our own actions. And this finitude is something 
we experience when acting out of chance, as we discover how our original plans were transformed into something unforeseen. But this means that the phenomenon of chance indicates a finitude pertaining to the agent's perspective on his own actions, so that his knowledge of what he himself is doing actually is open to revision in the light of new experiences. And when a new, unintended end presents itself, it naturally seems to have an external origin, namely, in relation to the agent's own initial conception of his action, but therein is also implied that the agent is granted an incentive to reinterpret his action in the light of its result and possibly to affirm the chance end as the true one. Thereby, he is the source and ground of his action in the sense of being the one who not only experiences and in general relates to its external factors, but also in such a way as to take these conditions upon himself. In other words, when chance intervenes into the course of action initiated by the agent, it certainly appears as the limit of finality, though not of finality as such (as has often been suggested), but of the specific finality anticipated by the agent. It is along these lines that we should understand the phrase "it just happened by accident that he went away, and did this for the sake of collecting the money" in our quotation from the Physics: even though the action was not originally performed for the sake of the actual result, that very result eventually presents itself as a goal that is possible to pursue. This is not to suggest that we commonly discover that we do in fact have ends in mind of which we are unaware, but that we so to speak integrate what happens by chance into our story about ourselves, and in this way reassess the particular intelligibility or rational order that constitutes our existence. For this reason, even though chance actions do not terminate in the expected result, they should not be regarded as failed actions, but as actions that are reinterpreted as they unfold.

As I see it, there is not necessarily anything dramatic about the occurrence of chance: my experience of my finitude as an agent does not necessarily consist in the perplexing discovery that I am in fact not the cause of everything. Rather, I experience how the world appears in ways contrary to my expectations, which is not to say that the world constantly surprises me, but that it offers opportunities for action and thought which I could not calculate in advance, and in this way transcends my perspective and forces me to reevaluate my place in it. Thereby, I am able to view myself as from outside, that is, in relation to my initial aims and expectations, but this view from outside is, of course, ultimately from within, since it is my own perspective on myself. When thus regarded, the fact that agents are finite beings in causal respect does not constitute any threat against the notion of the agent as the arche of his or her actions, because even that which is not within our power to bring about is something we experience and respond to as subjects, and it is only in virtue of such a response that the external conditions are so to speak invited into the realm of agency and experienced as relevant within that context, namely precisely as external conditions. In other words, even in cases where the agent is not the source of his action, as in our example from the Physics, he is nonetheless its subject, because the action, including its cause, does not make any sense except in relation to the agent, as was also indicated above. But this means that, at bottom, the meaning of archê in connection with human agency does not depend on the distinction between internal and external causation, nor is it essentially a matter of physical or logical 
identity of agent and action. For the distinction between those two kinds of causes is made on the basis of a model of production, which conceives of prâxis as a process that leads to a certain result and as such may be captured in objective terms.

Remember that Aristotle denies that we deliberate about the ends: it is essentially our character that determines what goals we choose to pursue. And under normal circumstances, a given situation of action offers a variety of possible ends to pursue (collecting one's money, seeing a spectacle, escaping someone, etc.) which do not have us as their source and which therefore, in relation to our initial wishes and deliberations, appear as unexpected and "chance" ends. But whether it is our own character or accidental circumstances that constitute the origin of the ends we strive to attain, the moment we respond to an end it becomes a possible reason for action, and as such both the end and its causes are open to reflection and critical assessment. To use Aristotle's expression, this is the moment when desire becomes deliberate desire (cf. E.N. 1113a10-11). The point is thus not to deny the existence of causality in agency, but to claim that all causes, whether external or internal, are relevant to our explication of action only insofar they are accessible to the agent as possible reasons.

Accordingly, what I want to suggest is that the case of chance shows us what it takes to do justice to the phenomenon of action as a rational, intentional activity, instead of subsuming it under the model of production. Chance actions are exemplary in this respect, since from a causal perspective, they simply do not count as actions at all. As such, they enable us to see that the agent is the arche of his actions in virtue of being the vehicle of their internal logic or rationality, which certainly may seem to be extinguished by the intervention of chance, but which in fact gets reinterpreted in the light of chance, as the expected and unexpected interconnect. In other words, the agent is first of all the one who provides the action with its sense and content, which is not to say that he is a self-sufficient source of meaning, as if his understanding of, for example, the moral significance of his actions were not dependent on the views of his fellow men. The point is that it takes a first-person perspective to make sense of and relate to such phenomena as (other people's views on) moral import: they are not objects that can be observed from outside. Besides, the agent's comprehension of his own action is also finite in the sense that it is not necessarily complete only because that particular action has been carried out, for actions continue to be assessed and evaluated after they have been completed. That Aristotle too holds this view is at least suggested by his claim that an action may turn out to be involuntary if the agent regrets it afterwards (E.N. 1110b22-23)..

A further consequence of this perspective is that action cannot be described as exclusively oriented towards the future, which is supposedly the very essence of teleology. But in the Physics, Aristotle indicates that human agency has to be explicated within the framework of a wider temporal horizon: apart from forward-looking (towards future ends), an action also involves backward-looking in the direction of past ends, for these are what appears in a new light or gets reevaluated when we act by chance, which then sets the stage for a new anticipation of other future ends, and so on. This hermeneutic process is not easily captured with the concept of deliberation, since this is so intimately connected with calculation, which makes it look as if action must be a self-contained affair: as if action would merely be a 
matter of deliberating about the means and then leading them back to oneself as to the efficient cause of action. But when thus conceived, action, in the case it achieves something different from the originally intended end, or with means that were not in the agent, will look like just a sub-species of production.

The interpretation of chance and human agency I have developed here certainly moves beyond what is explicitly stated in Aristotle's own text. But such an interpretation is called for, I think, if one is to make sense of his notion of the agent as the ground and origin of action, and in general of his distinction between action and production. These two concepts do not primarily refer to two different ontological categories but rather to two different conceptions of human agency: the one centering on causes and effects, the other on reasons and meaning. An action is simply that which is done for a reason and which therefore is subject to praise and blame; we may of course also regard human behavior as an event with causes and effects just like any other natural process, but this means that we are not talking about an action any more. Hence, only if the concept of archê is understood in terms of sensegiving and subjectivity is it possible to fully affirm an ethical perspective on agency, since reasons rather than causes are what is relevant to moral issues. In this sense, the realm of human agency is indeed complete and self-sufficient, just like Aristotle said, for what this means is that an action must be explicated as well as evaluated solely on the basis of itself, without being related to natural causation, which move only would lead us to the impossible question of whether or not we "really" are free and as such responsible agents. ${ }^{41}$

By way of conclusion, I would like, if only very briefly, to look at Aristotle's concept of chance in a historical light. On comparison, what he discusses under the heading of chance might seem to only have the name in common with the tuche of Greek Tragedy, which displays chance or fate as an independent power against which man is helpless. But maybe Aristotle's account of chance can help to explain the rationale behind the rather harsh ethics of tragedy, namely, that it is no excuse that you were, for example, from birth destined to kill your father, you are still responsible for it: this is precisely because, once chance is tied to the realm of human agency, it only has reality insofar as it is fulfilled by agents who make sense of it and in this way constitute its archê. And as Aristotle says, for that of which we are the archê we are also responsible (E.N. 1110b13-15).

\footnotetext{
${ }^{1}$ Attempts to resolve this apparent inconsistency can be found in D. M. Balme, "Greek Science and Mechanism: I. Aristotle on Nature and Chance," The Classical Quarterly 33:2 (1939): 129-138; Dorothea Frede, "Accidental Causes in Aristotle," Synthese 92 (1992): 39-62; James G. Lennox, "Teleology, Chance, and Aristotle's Theory of Spontaneous Generation," Journal of the History of Philosophy 20:3 (1982): 219-238; Willard M. Miller, "Aristotle on Necessity, Chance, and Spontaneity," New Scholasticism 47 (1973): 204-213; Richard Sorabji, Necessity, Cause and Blame: Perspectives on Aristotle's Theory (London: Duckworth, 1980); Wolfgang Wieland, "The Problem of Teleology," Articles on Aristotle 1. Science, J. Barnes, M. Schofield \& R. Sorabji, eds. (London: Duckworth, 1975), 141-160.

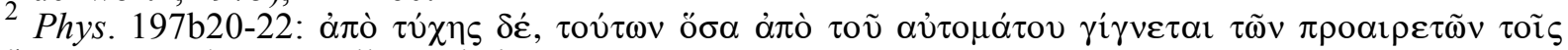

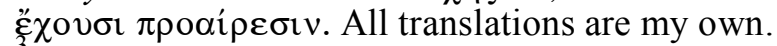

See Balme, "Greek Science and Mechanism," 129; Francesca Filippi, "Dynamis, Causality and Chance in Aristotle," Hasard et nécessité dans la philosophie greque, Evanghélos Moutsopoulos, ed. (Athens: Académie d'Athène, 2005), 111-129; Lindsay Judson, "Chance and 'Always or For the Most Part' in Aristotle," Aristotle's Physics: A Collection of Essays, L. Judson, ed. (Oxford: Clarendon Press, 1991), 73-99; Auguste Mansion, Introduction à la physique Aristotélicienne (Louvain: Éditions
} 
de l'institut supérieur de philosophie, 1946), Ch. VII, in particular 304ff; Pascal Massie, "The Irony of Chance: On Aristotle's Physics B, 4-6," International Philosophical Quarterly 43:1 (2003): 15-28; Miller, "Aristotle on Necessity, Chance, and Spontaneity," 208-209; Robin Smith, "Filling in Nature's Deficiencies," Aristotle's Ontology, A. Preus \& J. P. Anton, eds. (Albany: SUNY Press, 1992), 293312 , in particular 303. James Lennox, who also supports this view, refers it to Simplicius' interpretation of the Physics, "Aristotle on Chance," Archiv für Geschichte der Philosophie 66 (1984): $52-60$.

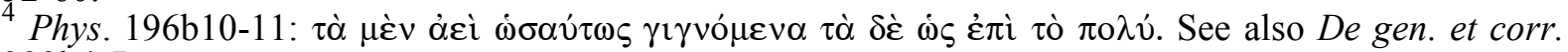
$333 \mathrm{~b} 4-7$.

In his so-called Natorp-Bericht, "Phänomenologische Interpretationen zu Aristoteles: Anzeige der hermeneutischen Situation" (Dilthey-Jahrbuch 6 [1989]: 237-269), Heidegger remarks that Aristotle's treatment of chance in the Physics "is of decisive importance with respect to the problem of facticity," 266. Even though in the following I will not be directly concerned with Heidegger's interpretation of Aristotle, the argument that I develop could to some extent be regarded as a response to this claim of Heidegger's.

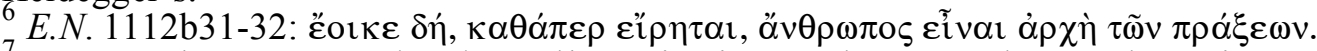

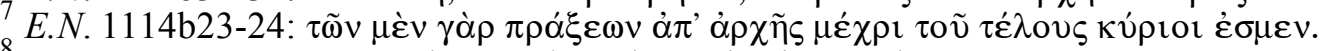

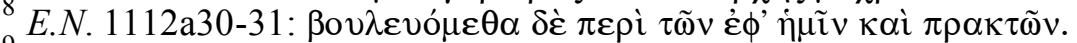

9 E.E. 1222b41-1223a9:

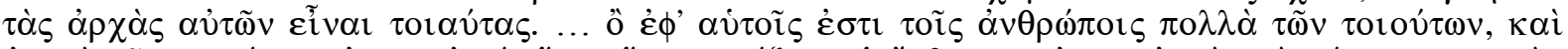

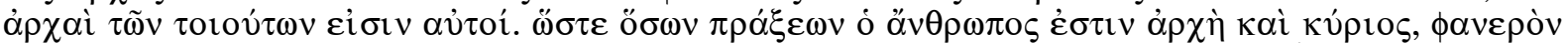

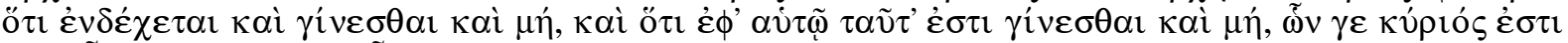

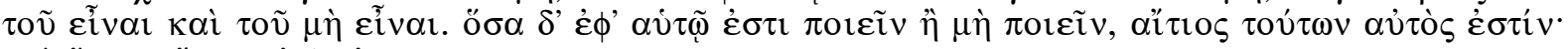

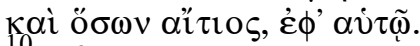

Cf. E.N. 1139a31-33. Strictly speaking, "for the sake of which" has a twofold meaning: if I take a walk in order to improve my health, good health is the end of this action (in the sense of its anticipated outcome), but that for the sake of which the action is carried out is in one sense good health, and in another sense me, since I am the one who will benefit from the walk. Cf. Monte R. Johnson, Aristotle on Teleology (Oxford: Clarendon Press, 2005), 64-80.

This aspect of Aristotle's ethics has been emphasized by John McDowell, e.g. in "Two Sorts of Naturalism," Mind, Value, and Reality (Cambridge: Harvard University Press, 1998), 167-197.

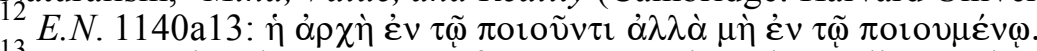

${ }^{13}$ To use Aristotle's concept of cause, aitia, in order to discern the different aspects of archê naturally requires that we understand aitia in the broad sense of explanation rather than simply as cause, which is also quite common today; see Julia Annas, "Aristotle on Inefficient Causes," Philosophical Quarterly 32 (1982): 311-326, in particular 319. But this line of interpretation has been criticized by Cynthia A. Freeland, “Accidental Causes and Real Explanations," Aristotle's Physics: A Collection of Essays, 49-72.

See E.N. I.7, e.g. 1097b20-21: "Happiness thus appears as something perfect and self-sufficient,

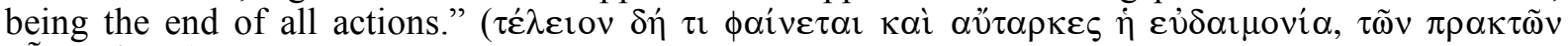

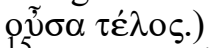

E.N. 1099b9-23, 1153b21-24. But see Emil Angehrn, "Glück und Gelingen," Studia Philosophica 56 (1997): 125-138, who argues that Aristotle's conception of eudaimonia as the highest end of human life nonetheless involves an aspect of luck, and therefore also of chance, despite the fact that Aristotle himself at E.N. 1099b20-25 rejects the view that happiness could be a matter of luck, as it is on the contrary entirely in accordance with the order of nature.

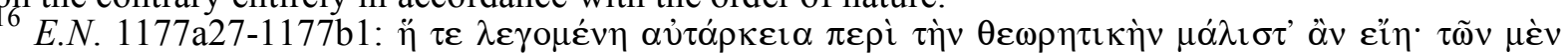

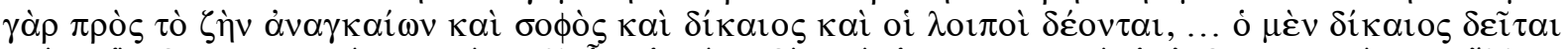

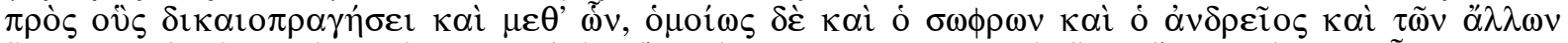

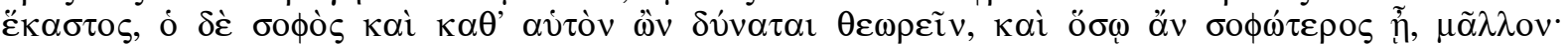

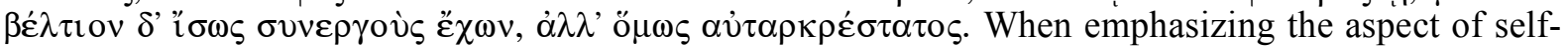
sufficiency in Aristotle's conception of the good life, I am mainly interested in its implications for his notion of the agent as a ground for action. I do not necessarily wish to defend an "intellectualist" interpretation of Aristotle's ethics, which holds that the good life is fundamentally or perhaps only a matter of theoretical activity, rather than involving both contemplation and morally virtuous activity, which is the position taken by the so-called inclusivist reading of the Nicomachean Ethics. For a recent attempt to respond to this debate, see Hope May, Aristotle's Ethics: Moral Development and Human Nature (London \& NY: Continuum, 2009).

That such a model is indeed central to Aristotle's philosophy as a whole, and perhaps most obviously to his philosophy of nature, is generally acknowledged today. The most systematic attempt to give a critical assessment of Aristotle's work in this respect is probably still that developed by Heidegger; see e.g. Grundprobleme der Phänomenologie (Frankfurt am Main: Klostermann, 1975), § 
11 and Platon: Sophistes (Frankfurt am Main: Klostermann, 1991), § 42b $\beta$. As regards Aristotle's theory of action, Sarah Broadie has argued that Aristotle cannot help but conceive of the end of action in terms of production, since only the latter has a specific content. By contrast, the end that Aristotle says characterizes action, namely successful action, is on her view empty and impracticable; Ethics with Aristotle (NY \& Oxford: Oxford University Press, 1991), Ch. 4.III. A decisively appreciative evaluation of this aspect of Aristotle's thought is given by Hope, Aristotle's Ethics, who offers a "developmentalist" reading of the Nicomachean Ethics that puts precisely the making of virtuous action into focus. In Aristotle's Philosophy of Action (NY: Cornell University Press, 1984), David Charles, too, strongly emphasizes the role of causal explanation in Aristotle's theory of action (see in particular Ch. 2), even though he also holds it to be one of the advantages of Aristotle's account of action that it combines causal explanation with teleological considerations, 59.

${ }^{18}$ More precisely, Aristotle accuses (in Phys. II.4) his predecessors of failing to see chance where it actually appears, whereas they attribute to chance and spontaneity such things that are in fact not so determined. See also De gen. et corr. II.6. For a discussion of Aristotle's criticism on this point, see John Dudley, "Necessity and Chance: Aristotle's Criticism of the Presocratics," Hasard et nécessité dans la philosophie grecque, 92-110.

E.N. 1140a17-20; see also Met. 1034a9-10 and 1065a27ff, where it is said that chance and thought are concerned with the same sphere.

${ }^{20}$ However, Aristotle appears from time to time to leave room for chance in an objective sense, as when he speaks about chance in connection with natural generation (e.g. Met. 1032a25-32), though this is better described as a case of spontaneity, which also is the term Aristotle usually prefers in this context.

${ }^{21}$ Cf. note 3, above, in particular Smith, "Filling in Nature's Deficiencies," 300. See also Friedrich Solmsen, Aristotle's System of the Physical World: A Comparison with his Predecessors (Ithaca: Cornell University Press, 1960), Ch. 5, in particular 104-106. Zev Bechler, Aristotle's Theory of Actuality (Albany: SUNY Press, 1995), suggests that luck (which is how Bechler translates tuchê) is in fact just a "mere word," which does not carry any "positive meaning," 65. This is also how the atomists' views on chance often have been understood; cf. Lowell Edmunds, "Necessity, Chance, and Freedom in the Early Atomists," Phoenix: The Journal of the Classical Association of Canada 26 (1972): 342-357, in particular 350, 353-354.

22 "The Irony of Chance," 28.

${ }_{24}^{23}$ E.g. Iliad, Book 4, line 106, Book V, line 98, 279, 287, 579.

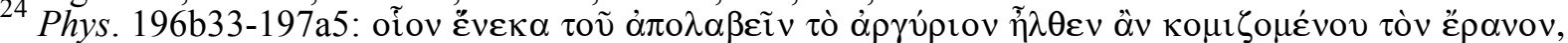

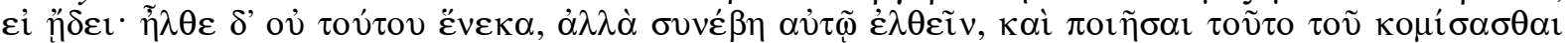

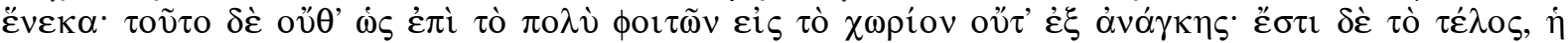

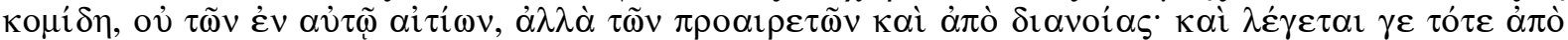

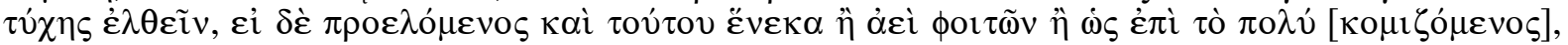

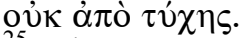

${ }^{25}$ I thus agree with William Charlton's suggestion that it is the meeting with the debtor, rather than the opportunity to recover the debt, that is due to chance in this example; see Aristotle's Physics: Books I and II (Oxford: Clarendon Press, 1992/1970), 107-108.

${ }_{27}^{26}$ Cf. Miller, "Aristotle on Necessity, Chance, and Spontaneity," 209.

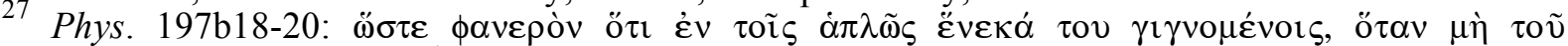

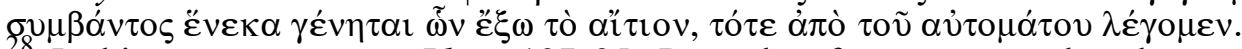

28 In his commentary to Phys. 197a25, Ross therefore suggests that, here, we should understand heneka not as "for the sake of" the actual outcome but as "producing an end-like result," Aristotle's Physics (Oxford: Clarendon Press, 1936), 520. This is also the standard interpretation of chance referred to in the beginning of this article; cf. note 3 . Johnson, however, has suggested that chance is indeed a cause, though not an explanatory cause, since it is secondary to nature as the proper, intrinsic cause behind natural processes, Aristotle on Teleology, 95-104.

9 Marcelo D. Boeri seems to me to come close to such an interpretation of Aristotle's teleology when he argues that we must take seriously Aristotle's claim at Phys. 196b21-22 that "That which is for the

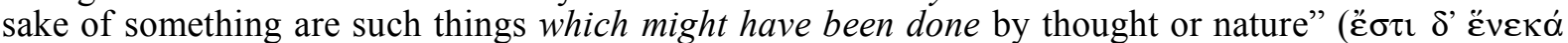

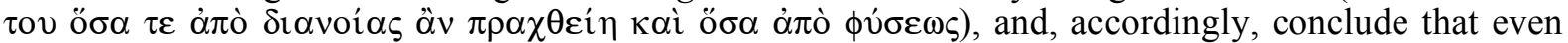
chance events do have ends "in some way," though these ends were not intended at the outset, "Chance and Teleology in Aristotle's Physics," International Philosophical Quarterly 35:1 (1995): 87-96, especially 95.

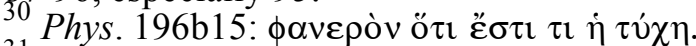

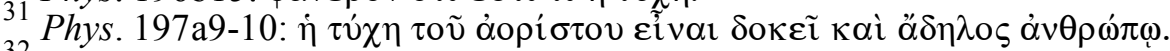

32 It does not matter, of course, whether or not the agent actually achieves the originally intended end, so that he both recovers his money and e.g. sees a spectacle, for the action we are considering is the 
chance action, which cannot be said to terminate in the opportunity to see a spectacle, because then it is no longer regarded as a chance action.

I believe this is the point Anscombe wants to make when she claims that the kind of knowledge that is involved in action is not knowledge by observation: you are not the spectator of your own action, registering as from outside different facts about it, such as what intention governs it, and in general how it should be described. For the consequence of that kind of perspective is that knowledge, and intention in general, becomes something additional in relation to the action itself, so that action is regarded as mere behavior plus intention; see Intention (Oxford: Blackwell, 2000/1957), § 8.

This is sometimes taken to mean that chance is simply "irrational." Thus Charlton translates this sentence as "it is right to oppose luck to the accountable," Aristotle's Physics: Books I and II, 35, and Hans Wagner renders it as "verstoße gegen all Begreifbarkeit," Aristoteles, Physikvorlesung (Berlin: Akademie Verlag, 1995), 46. But Aristotle is after all trying to make sense of chance in the Physics!

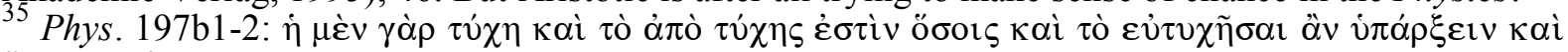
ӧ $\lambda \omega \varsigma \pi \rho \tilde{\alpha} \xi 1 \varsigma$.

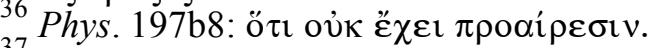

${ }^{37}$ This is a point on which Broadie criticizes Aristotle's theory of action, as she thinks that it makes him incapable of distinguishing voluntary from intentional action, Ethics with Aristotle, 137.

Hence, Bechler concludes about the coincidental as such that it "is not a reality," for "just as it is strictly the cause of nothing, so it is, strictly, nothing," Aristotle's Theory of Actuality, 65.

${ }_{40}$ Massie, "The Irony of Chance," 15.

40 However, I suspect that the following attempt to make room for chance within a teleological conception of human agency would count as an attempt to "re-appropriate" chance by teleology, in the sense discussed and criticized by Massie, "The Irony of Chance," 25-26, who for his own part wants to regard chance as an irreducible factor and ultimate aporia.

${ }^{41}$ However, that Aristotle should be, and indeed is engaged in that kind of question has been suggested by T. H. Irwin, "Reason and Responsibility in Aristotle," Essays on Aristotle's Ethics, Amélie Oksenberg Rorty, ed. (Berkely: University of California Press, 1980), 117-155. 